\title{
Effect of Feeding and Obesity on Lipoprotein Lipase Activity, Immunoreactive Protein, and Messenger RNA Levels in Human Adipose Tissue
}

John M. Ong and Philip A. Kern

Division of Endocrinology, Department of Medicine, Cedars-Sinai Medical Center, Los Angeles, California 90048

\begin{abstract}
Previous studies have demonstrated higher levels of adipose tissue lipoprotein lipase (LPL) catalytic activity in obese subjects, and in response to a meal. To examine the cellular mechanism of this increase in activity, LPL activity, immunoreactive mass, and mRNA level were measured in lean and obese subjects both before and $4 \mathrm{~h}$ after a carbohydrate-rich meal. Heparin-releasable (HR) LPL activity was $\sim 2.5$-fold higher in the 15 obese subjects, when compared with six lean subjects. However, there was no difference in LPL immunoreactive mass between the lean and obese subjects. In response to the meal, there was a 2.2-fold increase in total adipose tissue LPL activity in the lean subjects due to an increase in both the HR fraction, as well as the adipose fraction extracted with detergents. However, no increase in LPL immunoreactive mass was observed in any adipose tissue LPL fraction, resulting in an increase in LPL specific activity in response to the meal. In the obese subjects, there was no significant increase in LPL activity in response to feeding, and also no increase in immunoreactive mass or specific activity. After extraction of RNA, there was no difference in either the relative proportion of the 3.6and 3.4-kb human LPL mRNA transcripts, nor in the quantity of LPL mRNA in response to feeding. Thus, these data suggest that the increase in LPL activity under these conditions occurs through a posttranslational activation of a previously inactive LPL precursor.
\end{abstract}

\section{Introduction}

In previous studies of the regulation of adipose tissue lipoprotein lipase (LPL), ${ }^{1}$ a constant finding has been the increase in tissue LPL activity after feeding (1). Because LPL is responsible for the hydrolysis of triacylglycerols contained in circulating triglyceride-rich lipoproteins, the meal-stimulated increase in LPL activity plays a homeostatic function to facilitate lipid clearance and promote adipose tissue storage $(1,2)$. Much evidence suggests that the insulin response to a meal is an important part of the response of LPL in adipose tissue. In addition to feeding, LPL activity was stimulated when insulin

Address reprint requests to Dr. Kern, Division of Endocrinology, Becker 131, Cedars-Sinai Medical Center, 8700 Beverly Blvd., Los Angeles, CA 90048.

Received for publication 15 September 1988 and in revised form 8 March 1989.

1. Abbreviations used in this paper: EXT, extractable; HR, heparin-releasable; LPL, lipoprotein lipase.

J. Clin. Invest.

(C) The American Society for Clinical Investigation, Inc.

0021-9738/89/07/0305/07 \$2.00

Volume 84, July 1989, 305-311 was administered to either normal subjects (3) or patients with diabetes (4), and when insulin was added to rat adipose tissue or cells in vitro (5-7).

Obese subjects have higher plasma insulin levels compared to lean subjects, as well as higher levels of LPL activity in their adipose tissue (8). Because of the importance of LPL in adipocyte triglyceride storage (1), the increased levels of LPL in obesity may be important to the maintenance of the obese state, and to the difficulty experienced by most obese patients with attempts at weight loss and weight maintenance.

Several studies suggested that the increase in adipose LPL with feeding in rats was dependent on the synthesis of new LPL protein (9-11), whereas other studies have suggested that glucose and insulin produce an activation of an inactive LPL precursor $(5,6)$. However, none of these studies measured the LPL protein directly. Although recent studies have demonstrated that isolated rat adipocytes in culture respond to insulin with an increase in LPL mRNA and synthetic rate (12), human adipocytes (13) and adipose tissue (14) do not respond to physiologic concentrations of insulin in vitro. Thus, the regulatory effects of feeding on LPL could operate through any of several cellular mechanisms.

With the recent availability of an immunoassay for the LPL protein (15), and the LPL cDNA (16), the mechanism of regulation of LPL can be studied. As described herein, LPL activity, immunoreactive mass, and mRNA levels were examined in lean and obese subjects both before and after a meal. These data demonstrate that posttranslational events play an important role in the regulation of this central enzyme to lipid metabolism.

\section{Methods}

Human subjects. We recruited 21 healthy subjects (6 lean and 15 obese) to study the effects of feeding or obesity on adipose tissue LPL. Subject characteristics are shown in Table I (subjects 1-10 were fed the test meal, and the other subjects had only basal fat biopsies). All subjects gave informed consent to the procedure, and none were diabetic, were taking any medications, or had any concurrent illness likely to affect lipid metabolism. All subjects had been at a stable weight for at least 1 mo before the study, and each subject was placed on an isocaloric diet, consisting of $50 \%$ carbohydrate, $20 \%$ protein, and $30 \%$ fat for the day before the biopsy. After fasting for $12 \mathrm{~h}$, a subcutaneous fat biopsy was performed from the lower abdominal wall. The biopsy was performed as described previously (17) by infiltrating $1 \%$ lidocaine (without epinephrine) in a square pattern, followed by a $3-\mathrm{cm}$ incision and removal of 3-10 $\mathrm{g}$ of fat. All subjects tolerated the procedure well.

To study the effect of feeding, a second biopsy was performed $4 \mathrm{~h}$ after consuming a high-carbohydrate test meal. The meal contained 1,100 calories from bread, jelly, and a carbonated beverage, and was consumed within $45 \mathrm{~min}$. Adipose tissue from each biopsy was immediately frozen in liquid nitrogen and stored at $-70^{\circ} \mathrm{C}$ for subsequent RNA extraction. A portion of the excised fat was immediately placed into iced PBS and processed within $1 \mathrm{~h}$ for LPL activity and immunoreactive protein as described below. 
Table I. Subject Characteristics

\begin{tabular}{|c|c|c|c|c|c|c|c|c|}
\hline Subject & Age/sex & Height & Weight & Body mass index & Triglycerides & Cholesterol & HDL & Glucose \\
\hline & & $m$ & $k g$ & $\mathrm{~kg} / \mathrm{m}^{2}$ & $m g / d l$ & $m g / d l$ & $m g / d l$ & $m g / d l$ \\
\hline \multicolumn{9}{|l|}{ Normal } \\
\hline 1. & $21 \mathrm{M}$ & 1.73 & 65.9 & 22.1 & 92 & 137 & 91 & 91 \\
\hline 2. & $21 \mathrm{M}$ & 1.85 & 83.6 & 22.8 & 129 & 179 & 36 & 83 \\
\hline 3. & $40 \mathrm{~F}$ & 1.70 & 72.7 & 25.1 & 66 & 259 & 45 & 93 \\
\hline 4. & $35 \mathrm{~F}$ & 1.56 & 54.5 & 22.3 & 55 & 155 & 49 & 77 \\
\hline 5. & $34 \mathrm{~F}$ & 1.55 & 58.2 & 24.2 & 43 & 235 & 77 & 84 \\
\hline 6. & $32 \mathrm{~F}$ & 1.55 & 51.4 & 21.4 & 66 & 189 & 52 & 82 \\
\hline Mean \pm SE & $31 \pm 3$ & $1.66 \pm 0.05$ & $64.4 \pm 5.0$ & $23.0 \pm 0.6$ & $75 \pm 13$ & $192 \pm 19$ & $58 \pm 9$ & $85 \pm 3$ \\
\hline \multicolumn{9}{|l|}{ Obese } \\
\hline 7. & $43 M$ & 1.83 & 175 & 52.5 & 117 & 249 & 30 & 103 \\
\hline 8. & $43 \mathrm{M}$ & 1.70 & 153 & 52.8 & 134 & 164 & 34 & 93 \\
\hline 9. & $29 \mathrm{~F}$ & 1.65 & 84.5 & 31.0 & 62 & 210 & 82 & 65 \\
\hline 10. & $21 \mathrm{~F}$ & 1.75 & 90.9 & 29.6 & 28 & 193 & 80 & 96 \\
\hline 11. & $36 \mathrm{M}$ & 1.78 & 107 & 33.9 & 46 & 232 & 50 & 69 \\
\hline 12. & $33 \mathrm{M}$ & 1.85 & 115 & 33.3 & 91 & 203 & 29 & 80 \\
\hline 13. & $44 \mathrm{~F}$ & 1.80 & 126 & 38.9 & 62 & 199 & 46 & 83 \\
\hline 14. & $39 M$ & 1.85 & 150 & 43.8 & 105 & 205 & 35 & 83 \\
\hline 15. & $53 \mathrm{M}$ & 1.75 & 144 & 47.1 & 153 & 207 & 31 & 115 \\
\hline 16. & $47 M$ & 1.64 & 77.7 & 28.8 & 269 & 255 & 56 & 87 \\
\hline 17. & $45 \mathrm{M}$ & 1.83 & 197 & 58.9 & 176 & 241 & 55 & 95 \\
\hline 18. & $36 \mathrm{~F}$ & 1.63 & 114 & 42.8 & 75 & 209 & 32 & 91 \\
\hline 19. & $34 \mathrm{~F}$ & 1.78 & 86.4 & 27.3 & 96 & 203 & 58 & 78 \\
\hline 20. & $50 \mathrm{M}$ & 1.69 & 95.5 & 33.4 & 294 & 204 & 43 & 87 \\
\hline 21. & $45 \mathrm{~F}$ & 1.71 & 83.2 & 28.5 & 51 & 205 & 70 & 77 \\
\hline Mean \pm SE & $40 \pm 2^{*}$ & $1.75 \pm 0.02$ & $120 \pm 9.5^{*}$ & $38.8 \pm 3^{*}$ & $117 \pm 20$ & $212 \pm 6$ & $49 \pm 5$ & $87 \pm 3$ \\
\hline
\end{tabular}

${ }^{*} P<0.05$ vs. lean subjects.

LPL catalytic activity. LPL activity was determined as described previously (13) in two adipose tissue fractions: activity released with heparin (HR) and activity extracted from the tissue after the heparin release (EXT). The sum of HR plus EXT has previously been demonstrated to represent total adipose tissue LPL (13). For HR, freshly obtained adipose tissue was minced and incubated in PBS containing $13 \mu \mathrm{g} / \mathrm{ml}$ heparin (Fisher Scientific Co., Pittsburgh, PA) for $45 \mathrm{~min}$ at $37^{\circ} \mathrm{C}$. An aliquot of this buffer was then assayed as described below. The tissue was then washed in PBS and the EXT fraction was prepared by homogenizing the tissue in buffer containing deoxycholate and heparin, as described previously $(13,18)$. After centrifugation, the aqueous layer was recovered and an aliquot was assayed for LPL activity. In a previous study, the HR component of adipose tissue was shown to be essentially entirely LPL by antibody and salt inhibition (15). When similar experiments were performed with the EXT fraction of adipocytes, $65 \%$ of hydrolytic activity was inhibited with the antiLPL antibody, and $80 \%$ of activity was inhibited by high salt. Thus, lipolytic activity in the EXT fraction was also predominantly LPL.

LPL activity was determined as described previously (13) using a $\left[{ }^{14} \mathrm{C}\right]$ triolein-containing substrate emulsified with lecithin, and containing normal human serum as a source of apo CII. After incubating sample with substrate for $45 \mathrm{~min}$ at $37^{\circ} \mathrm{C}$, the reaction was stopped by adding Belfrage-Vaughn extraction mixture (19) and liberated ${ }^{14} \mathrm{C}$-free fatty acids were separated and quantitated by liquid scintillation. Activity was expressed as nanoequivalents of FFA released per minute per $10^{6}$ cells, and cell number was determined according to the method of DiGirolamo et al. (20).

LPL immunoreactive mass. The measurement of LPL immunoreactive mass by enzyme-linked immunosorbent assay (ELISA) has been described previously (15). In brief, a microtiter plate was coated with affinity-purified chicken anti-LPL antibody, and bovine LPL stan- dards and samples were added in a buffer containing $1 \mathrm{M} \mathrm{NaCl}, 0.1 \%$ Triton X-100, $0.1 \%$ albumin, protease inhibitors, and $25 \mathrm{mM}$ Tris$\mathrm{HCl}$ (pH 7.4). After the addition of biotinylated anti-LPL antibody followed by streptavidin-horseradish peroxidase (Bethesda Research Laboratories, Gaithersburg, MD), the plate was developed and read in an ELISA plate reader at $490 \mathrm{~nm}$.

Samples for LPL immunoreactive mass were prepared as described above for LPL activity, except for the presence of protease inhibitors (1 $\mathrm{mM}$ phenylmethylsulfonyl fluoride, $1 \mathrm{mM}$ benzamidine, $1 \mathrm{mM}$ EDTA, and $0.05 \mathrm{mM}$ aprotinin) in all the buffers. To determine whether the sum of HR plus EXT immunoreactive mass was an accurate estimation of total adipose LPL, HR plus EXT were compared to immunoreactive mass in homogenized adipose tissue (total LPL). In seven samples of fat, the mean values for HR, EXT, and total LPL were 12,53 , and $62 \mathrm{ng} / 10^{6}$ cells. Thus, the sum of HR plus EXT, 65 $\mathrm{ng} / 10^{6}$ cells, closely approximated the measured total LPL.

Western blotting. As described previously (15), samples of adipose tissue were homogenized without prior heparin release, using the deoxycholate-heparin buffer described above (with protease inhibitors and without albumin), and electrophoresed under denaturing conditions on a $12 \%$ polyacrylamide gel with a $3 \%$ stack. After electrophoretic transfer to nitrocellulose, the membrane was blotted with antiLPL antiserum, followed by incubation with rabbit anti-chicken antiserum (Sigma Chemical Co., St. Louis, MO) and ${ }^{125}$ I-protein A (Amersham Corp., Arlington Heights, IL).

Isolation of RNA and LPL mRNA quantitation. RNA was extracted from adipose tissue using the guanidinium-phenol-chloroform method of Chomczynski and Sacchi (21). RNA samples were either resolved by electrophoresis on a $2.2 \mathrm{M}$ formaldehyde-1\% agarose gel and transferred onto nylon membrane (Hybond-N; Amersham Corp.), or slot-blotted onto nylon membrane using a slot-blot manifold 
(Schleicher \& Schuell, Inc., Keene, NH). cDNA probes coding for human LPL (16) and $\gamma$-actin (22) were radiolabeled by the randompriming method (23) with $\left[\alpha-{ }^{32} \mathrm{P}\right] \mathrm{dCTP}(3,000 \mathrm{Ci} / \mathrm{mmol}$; ICN Biomedical, Irvine, CA). The membranes were prehybridized in a solution containing $5 \times$ SSC, $5 \times$ Denhardt's solution, $0.05 \mathrm{M}$ sodium phosphate (pH 7.5), $0.1 \%$ (wt/vol) SDS, $200 \mu \mathrm{g} / \mathrm{ml}$ denatured salmon sperm DNA, and $10 \%(w t / v o l)$ dextran sulfate. The $\left.{ }^{32} \mathrm{P}\right] \mathrm{cDNA}$ probes $(1$ $\times 10^{6} \mathrm{cpm} / \mathrm{ml}$ ) were hybridized to the blotted membrane in the same solution as above, except for the addition of $50 \%$ (vol/vol) formamide. The blots were washed twice with $2 \times \operatorname{SSC}(0.3 \mathrm{M}$ sodium citrate, $0.3 \mathrm{M}$ sodium chloride) with $0.1 \%$ (wt/vol) SDS at room temperature and twice with $0.2 \times \mathrm{SSC}, 0.1 \% \mathrm{SDS}$ at $60^{\circ} \mathrm{C}$. The blot was dried at room temperature and exposed to XAR-5 X-ray film (Eastman Kodak Co., Rochester, NY) at $-70^{\circ} \mathrm{C}$. Autoradiographic images were quantitated by densitometry, and there was a linear relationship between RNA loaded and the LPL mRNA signal.

Statistics. All data were expressed as the mean \pm SEM and were analyzed nonparametrically using the Wilcoxon matched-paired signed-rank test for paired data, and the Mann-Whitney rank sum test for nonpaired data.

\section{Results}

In Table I, characteristics of the subjects described herein are shown. Subjects were assigned to the "obese" group if the body mass index was $>27$. Although several subjects had mild elevations of either serum triglycerides or cholesterol, there were no significant differences between the groups with regards to fasting lipids or blood glucose.

In all 21 subjects, the adipose tissue biopsy was performed in the fasting state, and LPL activity and immunoreactive mass were measured. As shown in Fig. 1, obese subjects had significantly greater adipose LPL activity when compared with lean subjects. This was due to the increased HR activity, inasmuch as there was no significant difference in EXT activity
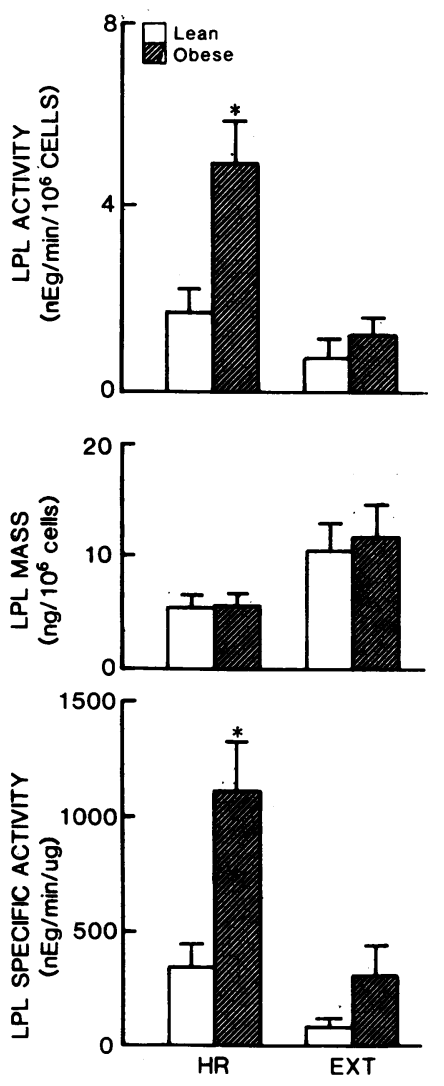

Figure 1. Fasting LPL activity, immunoreactive mass, and specific activity in lean and obese subjects. After a 12-h fast, 6 lean and 15 obese subjects underwent a subcutaneous adipose biopsy, and LPL activity and immunoreactive mass were measured in the HR and EXT fractions (see Methods). LPL specific activity was calculated by dividing activity by mass. ${ }^{*} P<0.05$ vs. lean subjects. between lean and obese subjects. In spite of this difference in LPL activity, there was no difference between the lean and obese groups in LPL immunoreactive mass in either HR or EXT. Therefore, the adipose LPL of the obese subjects was characterized by LPL of higher specific activity, due mainly to the increased specific activity of the HR enzyme.

The effects of a carbohydrate-rich meal on adipose LPL were examined in six lean subjects and four obese subjects (subjects 1-10 in Table I). As shown in Fig. 2, there was a significant increase in LPL activity in response to the meal in the lean subjects, and no significant increase in the obese subjects. However, there was no significant increase in LPL immunoreactive mass from either lean or obese subjects. This resulted in an increased specific activity of adipose LPL in response to the meal in the group of lean subjects. To confirm the lack of change in LPL immunoreactive mass and to examine the forms of LPL, the pre- and postmeal samples from a representative lean subject were Western-blotted. As shown in Fig. 3, there was no change in the quantity of LPL in the adipose tissue before and after feeding, nor was there any difference in migration of the LPL protein on the gel.

To determine whether the increase in specific activity in response to feeding was due to changes in HR or EXT, LPL activity and mass in these two fractions were examined separately. As shown in Fig. 4, increases in LPL activity with feeding were seen in both the HR and EXT fractions of lean subjects, and no significant changes were seen in either fraction from obese subjects. In neither lean nor obese subjects, however, was there an increase in LPL immunoreactive mass.

To further study the mechanism of regulation of LPL, the level of LPL mRNA was examined in adipose tissue of subjects before and after feeding. As shown in Fig. $5 \mathrm{~A}$, Northern blot analysis of total RNA from two representative subjects revealed the 3.6- and 3.4-kb LPL transcripts, as described previously in human tissues (16). To control for sample loading and recovery, the blots were also hybridized with the cDNA to $\gamma$-actin. In spite of increases in LPL activity and specific activity with feeding, the quantity of LPL mRNA was unchanged when compared to the message for $\gamma$-actin. In addition, the relative proportions of the 3.6- and 3.4-kb LPL mRNA species remained approximately equal in pre- and postmeal samples. To more precisely quantitate the changes in LPL mRNA with feeding, the pre- and postmeal samples were slot-blotted and

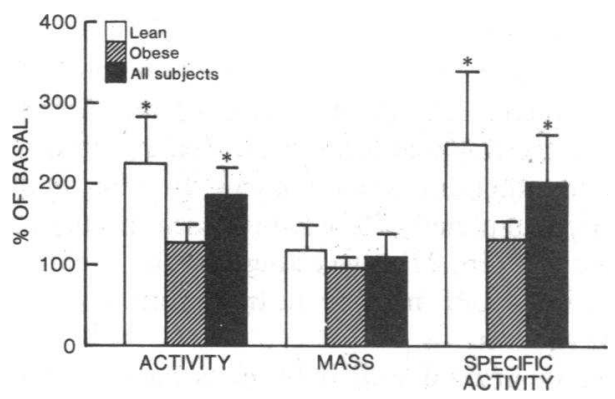

Figure 2. Effect of feeding on total adipose LPL. After a 12-h fast, six lean and four obese subjects underwent an adipose biopsy, and then consumed an 1,100-calorie high-carbohydrate meal within $45 \mathrm{~min}$. A second biopsy was then performed $4 \mathrm{~h}$ later. Total adipose tissue LPL (HR plus EXT) activity, immunoreactive mass, and specific activity was determined as described in Methods, and the results expressed as the percent of the basal (fasting) value. ${ }^{*} P<0.05$ vs. fasting. 


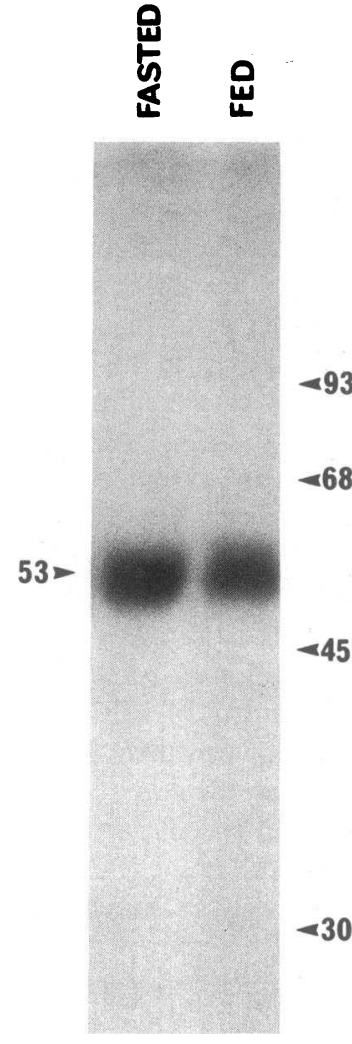

LPLa 1.9 3.0

LPLm 25
Figure 3. Western blot of pre- and postmeal adipose tissue. Protein was extracted from whole adipose tissue as described in Methods and equal amounts of extracted material were electrophoresed, transferred, and blotted with antiLPL antiserum, as described in Methods. One of three representative Western blots is shown. LPL activity (LPLa, neq/min per $10^{6}$ cells) and LPL immunoreactive mass (LPLm) from each sample is shown below each lane.

probed with the cDNAs for both LPL and $\gamma$-actin. These blots were analyzed by densitometry and the LPL/actin mRNA ratio from the postmeal biopsies was compared to the ratio from the pre-meal samples. As shown in Fig. $5 \mathrm{~B}$, there was no increase in the LPL/actin mRNA ratio from either lean or obese subjects with feeding. Thus, just as the increase in LPL activity with feeding was accompanied by no increase in LPL immunoreactive mass, there was also no increase in LPL mRNA content in the adipose tissue.

\section{Discussion}

Numerous previous studies have measured the response of LPL activity to changes in nutritional state (for review, see Eckel [1]). In both rats and humans, LPL activity is higher in the adipose tissue in the fed state than in the fasted or hypocaloric state. In some studies, the increase in whole tissue LPL activity was not accompanied by an increase in isolated adipocyte LPL $(24,25)$, suggesting that feeding induced an increase in extracellular or endothelium-bound enzyme. In other studies, however, the heparin-eluted LPL was increased in isolated adipocytes from fed rats $(26,27)$, suggesting that the heparinreleased form of adipose LPL may be an important, regulatable fraction of the enzyme.

Feeding studies in normal weight humans have consistently measured increases in HR activity within 4-6 h after a carbohydrate-rich meal $(8,28-30)$. This increase in HR correlated with the rise in serum insulin level, and was not seen in patients with diabetes (8). However, the magnitude of the increase was quite variable in different subjects, and obese subjects demonstrated no increase in LPL activity with feeding
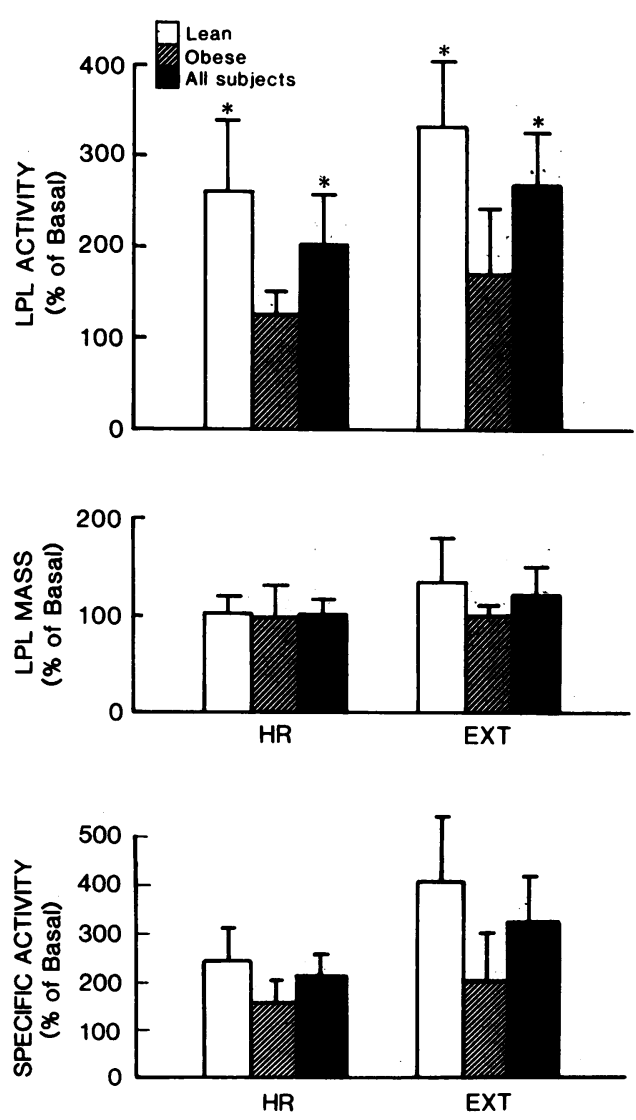

Figure 4. Effect of feeding on HR and EXT LPL. In the pre- and postmeal adipose tissue samples, LPL activity and immunoreactive mass were measured as the HR and EXT components (see Methods), and specific activity was calculated as described for Fig. 1. The effects of feeding on HR and EXT are expressed as the percentage of the basal (fasting) value. ${ }^{*} P<0.05$ vs. fasting.

$(30,31)$. In addition, after feeding normal subjects a high fat meal, no significant increase in LPL was observed (8), and fat ingestion also blunted the increment in LPL after an insulin infusion (32). Thus, the increase in LPL activity after a meal is related to the insulin sensitivity of the subject, the plasma insulin level, and the fat content of the test meal.

The experiments herein were designed to study the mechanism of the meal-induced increase in LPL activity. Both lean and obese subjects were recruited to undergo adipose tissue biopsies both before and after a high carbohydrate test meal. In agreement with previous studies, LPL activity in HR was increased $4 \mathrm{~h}$ after the meal, and LPL activity was also increased in the EXT fraction. Previous studies also noted increases in LPL activity in whole adipose tissue using acetone-ether extraction $(8,33)$. However, in the absence of any direct measurement of the LPL protein, previous studies could not examine the mechanism of the increase in LPL with feeding. Although several studies in rat adipose tissue used indirect methods to suggest that the increase in LPL activity was due to an increase in LPL protein (9-11), none of these studies measured the LPL protein directly with an immunoassay.

To examine LPL immunoreactive mass, HR and EXT were prepared from the same adipose tissue samples used for LPL activity, and assayed in the ELISA described previously (15). No significant increase in LPL immunoreactive mass was 

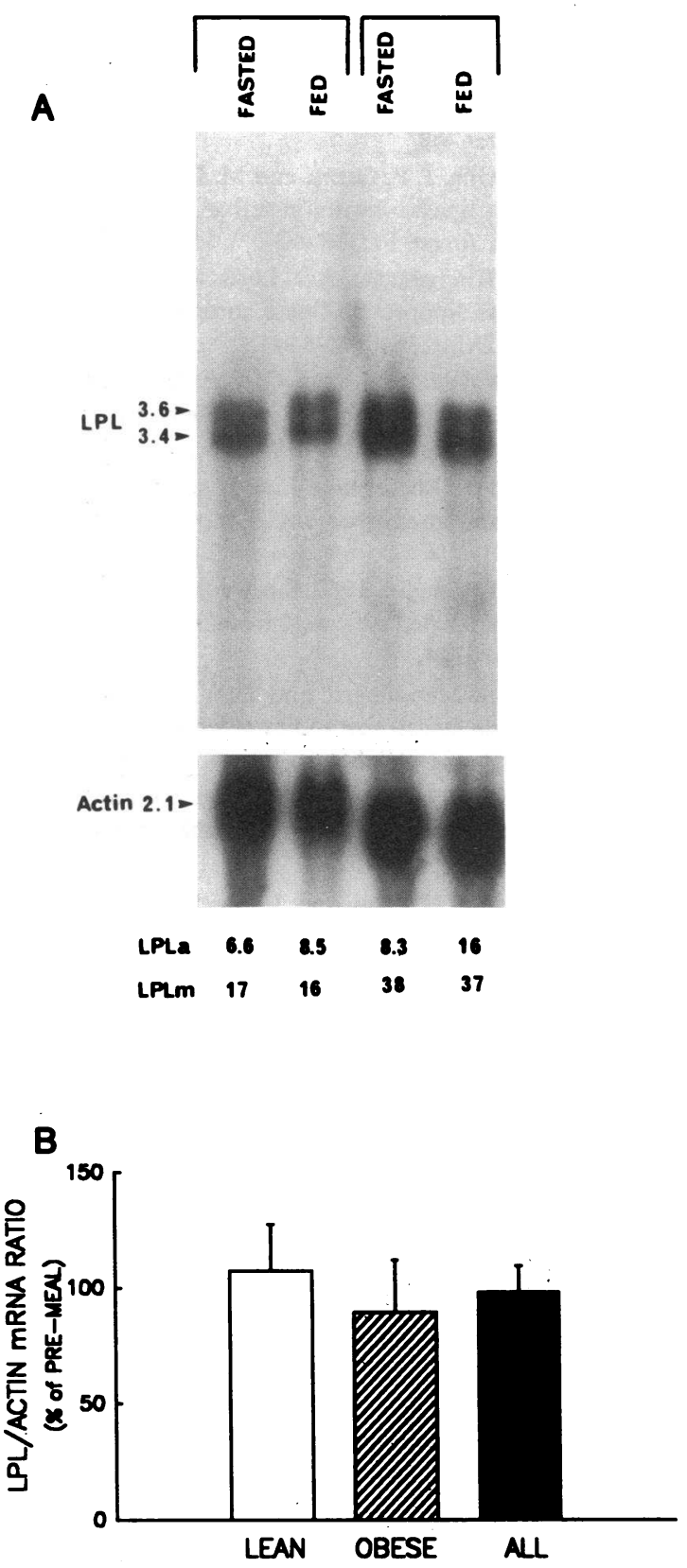

Figure 5. Effect of feeding on adipose tissue LPL mRNA. RNA was extracted from the pre- and postmeal adipose tissue samples. $(A)$ Northern blot of pre- and postmeal adipose tissue RNA from two representative subjects. $40 \mu \mathrm{g}$ of total RNA was used for each lane, and the blot was hybridized with the CDNA probes for LPL and $\gamma$ actin. LPL activity (LPLa) and immunoreactive mass (LPLm) from these patients are shown below each lane of the Northern blot. (B) Results of densitometric analysis of slot blots of total RNA from all the pre- and postmeal samples. For slot blotting, $10 \mu \mathrm{g}$ of total RNA was loaded onto the manifold. The postmeal LPL/actin mRNA ratios are expressed as the percentage of the ratio during the fasted state. None of the changes in LPL/actin mRNA ratios were statistically significant.

seen in either HR or EXT. This lack of increase in LPL immunoreactive mass was confirmed by Western blot analysis, which also demonstrated that the postprandial form of adipose tissue LPL was not altered in molecular weight.
RNA was extracted from the adipose tissue, and subjected to analysis by Northern and slot-blotting. The blots were probed with the CDNA for human LPL (16), and the CDNA for $\gamma$-actin (22). The human LPL gene codes for two different-size LPL mRNAs $(3.4$ and $3.6 \mathrm{~kb})$ due to the presence of two polyadenylation sites on the LPL gene. There was no evidence of regulation of the two LPL transcripts, suggesting that the choice of the different polyadenylation sites under these circumstances is random. In addition, when the LPL message was quantitated and standardized to the message for $\gamma$-actin, there was no significant effect of feeding on the level of LPL mRNA.

Because feeding induced an increase in LPL activity with no increase in LPL immunoreactive mass or mRNA, these data suggest that feeding increased tissue LPL activity through a posttranslational activation of an inactive form of LPL. Exactly how this activation of LPL takes place, however, is not clear. Several studies have demonstrated that LPL is inactive when the enzyme is unglycosylated, such as after treatment of the cells with tunicamycin (34-37) or after culturing cells in the absence of glucose (37). However, the presence of LPL protein that was completely unglycosylated would have been apparent by Western blotting. Subtle changes in glycosylation would likely not be detected by Western blotting, however, and previous studies have demonstrated that other inhibitors of glycosylation result in the production of LPL with diminished activity $(34,38)$.

Previous studies have demonstrated that the addition of physiologic concentrations of insulin to cultured human adipocytes yielded no increase in either LPL activity or immunoreactive mass $(13,15)$. The in vivo administration of insulin, however, yielded an increase in LPL activity (3). The subjects in this study, and in other feeding studies, were undoubtedly hyperinsulinemic, and LPL activity increased. Therefore, these data suggest that the effect of a meal to stimulate LPL in humans does not occur through direct effects of insulin on the adipocyte. On the other hand, insulin increased LPL synthetic rate and mRNA levels in cultured rat adipocytes (12). Thus, the effects of insulin on rat adipocyte LPL may occur through a mechanism different from that in human adipocytes.

LPL is increased in the adipose tissue of obese humans, as well as in genetic and acquired models of rodent obesity (1), and this increased adipose LPL has been implicated in the pathophysiology of obesity (39). In the study described herein, HR activity of the obese subject group was $\sim 2.5$-fold higher than in the lean subjects, and there was no significant difference in EXT activity. LPL immunoreactive mass, however, was the same in each group, resulting in an higher LPL specific activity in the adipose tissue of obese subjects. Thus, the mechanism of the increased LPL in obese subjects is similar to the mechanism of the post-prandial LPL increase in lean subjects.

The similarity of mechanisms for increased LPL in fasting obese subjects and postprandial lean subjects suggests that these two states have common regulatory elements. Obese subjects have higher fasting insulin levels than lean subjects. Thus, insulin may be involved in the posttranslational regulation of human adipose LPL under both conditions. Obese subjects are also relatively hyperphagic. Thus, one explanation for the increased LPL specific activity in obese subjects is the constant stimulation of LPL by the increased caloric intake. However, such an explanation would not explain why adipose 
LPL activity is increased in many obese subjects after weight loss and stabilization (40).

In summary, these data demonstrate an increase in LPL activity in the adipose tissue of obese subjects, and in lean subjects after a meal. However, this increase in LPL activity was not accompanied by an increase in LPL immunoreactive mass, or in the level of LPL mRNA. Thus, the increase in LPL activity under these conditions occurs through a posttranslational activation of a previously inactive LPL protein.

\section{Acknowledgments}

We wish to thank Robert Martin and Joanne Carty for excellent technical assistance, as well as Sheryl Weber and Linda Gillman Purdy for assistance in recruiting subjects. The anti-LPL antibodies were supplied by Dr. John Goers, and the LPL cDNA probe was supplied by Drs. Todd Kirchgessner and Michael Schotz.

This study was supported by a fellowship grant from the American Diabetes Association/California Affiliate, grants AM-37085 and DK-39176 from the National Institutes of Health, and a Career Development Award from the Juvenile Diabetes Foundation.

\section{References}

1. Eckel, R. H. 1987. Adipose tissue lipoprotein lipase. In Lipoprotein Lipase. J. Borensztajn, editor. Evener Publishers, Inc., Chicago. 79-132.

2. Garfinkel, A. S., and M. C. Schotz. 1987. Lipoprotein lipase. In Lipoproteins. A. M. Gotto, Jr., editor. Elsevier, Amsterdam. 335-354.

3. Sadur, C. N., and R. H. Eckel. 1982. Insulin stimulation of adipose tissue lipoprotein lipase: use of the euglycemic clamp technique. J. Clin. Invest. 69:1119-1125.

4. Taskinen, M.-R., and E. A. Nikkila. 1979. Lipoprotein lipase activity of adipose tissue and skeletal muscle in insulin-deficient human diabetes: relation to high-density and very-low-density lipoproteins and response to treatment. Diabetologia. 17:351-356.

5. Ashby, P., D. P. Bennett, I. M. Spencer, and D. S. Robinson. 1978. Posttranslational regulation of lipoprotein lipase activity in adipose tissue. Biochem. J. 176:865-872.

6. Parkin, S. M., K. Walker, P. Ashby, and D. S. Robinson. 1980. Effects of glucose and insulin on the activation of lipoprotein lipase and on protein synthesis in rat adipose tissue. Biochem. J. 188:193199.

7. Eckel, R. H., J. E. Prasad, P. A. Kern, and S. Marshall. 1984. Insulin regulation of adipose tissue lipoprotein lipase in cultured rat adipocytes. Endocrinology. 114:1665-1671.

8. Pykalisto, O. J., P. H. Smith, and J. D. Brunzell. 1975. Determinants of human adipose tissue lipoprotein lipase: effect of diabetes and obesity on basal- and diet-induced activity. J. Clin. Invest. 56:11081117.

9. Spencer, J. M., A. Hutchinson, and D. S. Robinson. 1978. The effect of nutritional state on the lipoprotein lipase activity of isolated fat cells. Biochim. Biophys. Acta. 530:375-384.

10. Jansen, H., A. S. Garfinkel, J.-S. Twu, J. Nikazy, and M. C. Schotz. 1978. Regulation of lipoprotein lipase immunological study in adipose tissue. Biochim. Biophys. Acta. 531:109-114.

11. Parkin, S. M., B. K. Speake, and D. S. Robinson. 1982. Purification and characterization of rat adipose tissue lipoprotein lipase. Biochem. J. 207:485-495.

12. Ong, J. M., T. G. Kirchgessner, M. C. Schotz, and P. A. Kern. 1988. Insulin increases the synthetic rate and messenger RNA level of lipoprotein lipase in isolated rat adipocytes. J. Biol. Chem. 263:12933-12938.

13. Kern, P. A., S. Marshall, and R. H. Eckel. 1985. Regulation of lipoprotein lipase in primary cultures of isolated human adipocytes. $J$. Clin. Invest. 75:199-208.

14. Elkeles, R. S. 1974. Lipoprotein lipase in human adipose tissue. Clin. Sci. Mol. Med. 46:753-762.

15. Kern, P. A., J. M. Ong, J. F. Goers, and M. E. Petersen. 1988. Regulation of lipoprotein lipase immunoreactive mass in isolated human adipocytes. J. Clin. Invest. 81:398-406.

16. Wion, K. L., T. G. Kirchgessner, A. J. Lusis, M. C. Schotz, and R. M. Lawn. 1987. Human lipoprotein lipase complementary DNA sequence. Science (Wash. DC). 235:1638-1641.

17. Henry, R. R., P. Wallace, and J. M. Olefsky. 1986. Effects of weight loss on mechanisms of hyperglycemia in obese non-insulin-dependent diabetes mellitus. Diabetes. 35:990-998.

18. Iverius, P.-H., and A. M. Ostlund-Lindqvist. 1986. Preparation, characterization, and measurement of lipoprotein lipase. Methods Enzymol. 129:691-716.

19. Belfrage, P., and M. Vaughn. 1969. Simple liquid-liquid partition system for isolation of labeled oleic acid from mixture with glycerides. J. Lipid Res. 10:341-344.

20. DiGirolamo, M., S. Mendlinger, and J. W. Fertig. 1971. A simple method to determine fat cell size and number in four mammalian species. Am. J. Physiol. 221:850-858.

21. Chomczynski, P., and N. Sacchi. 1987. Single-step method of RNA isolation by acid guanidinium thiocyanate-phenol-chloroform extraction. Anal. Biochem. 162:156-159.

22. Gunning, P., P. Ponte, H. Okayama, J. Engel, H. Blau, and L. Kedes. 1983. Isolation and characterization of full-length cDNA clones for human $\alpha$-, $\beta$-, and $\gamma$-actin mRNA's: skeletal but not cytoplasmic actin have an amino-terminal cysteine that is subsequently removed. Mol. Cell Biol. 3:787-798.

23. Feinberg, A. P., and B. Vogelstein. 1983. A technique for radiolabeling DNA restriction endonuclease fragments to high specific activity. Anal. Biochem. 132:6-13.

24. Cunningham, V. J., and D. S. Robinson. 1969. Clearing-factor lipase in adipose tissue: distinction of different states of the enzyme and the possible role of the fat cell in the maintenance of tissue activity. Biochem. J. 112:203-209.

25. Nilsson-Ehle, P., A. S. Garfinkel, and M. C. Schotz. 1976. Intra- and extracellular forms of lipoprotein lipase in adipose tissue. Biochim. Biophys. Acta. 431:147-153.

26. Hansson, P., G. Nordin, and P. Nilsson-Ehle. 1983. Influence of nutritional state on lipoprotein lipase activities in the hypothyroid rat. Biochim. Biophys. Acta. 753:364-371.

27. Walks, D., M. Lavau, E. Presta, M.-U. Yang, and P. Bjorntorp. 1983. Refeeding after fasting in the rat: effects of dietary-induced obesity on energy balance regulation. Am. J. Clin. Nutr. 37:387-395.

28. Nilsson-Ehle, P., S. Carlstrom, and P. Belfrage. 1975. Rapid effects on lipoprotein lipase activity in adipose tissue of humans after carbohydrate and lipid intake: time course and relation to plasma glycerol, triglyceride, insulin levels. Scand. J. Clin. Lab. Invest. 35:373-378.

29. Goldberg, A. P., A. Chait, and J. D. Brunzell. 1980. Postprandial adipose tissue lipoprotein lipase activity in primary hypertriglyceridemia. Metab. Clin. Exp. 29:223-229.

30. Dahms, W. T., P. Nilsson-Ehle, A. S. Garfinkel, R. L. Atkinson, G. A. Bray, and M. C. Schotz. 1981. Lipoprotein lipase activity in adipose tissue from obese human beings. Int. J. Obes. 5:81-84.

31. Brunzell, J. D., R. S. Schwartz, R. H. Eckel, and A. G. Goldberg. 1981. Insulin and adipose tissue lipoprotein lipase in humans. Int. J. Obes. 5:685-694.

32. Sadur, C. N., T. J. Yost, and R. H. Eckel. 1984. Fat feeding decreases insulin responsiveness of adipose tissue lipoprotein lipase. Metab. Clin. Exp. 33:1043-1047.

33. Persson, B., B. Hood, and G. Angervall. 1970. Effects of pro- 
longed fast on lipoprotein lipase activity eluted from human adipose tissue. Acta Med. Scand. 188:225-230.

34. Chajek-Shaul, T., G. Friedman, H. Knobler, O. Stein, J. Etienne, and Y. Stein. 1985. Importance of the different steps of glycosylation for the activity and secretion of lipoprotein lipase in rat preadipocytes studied with monensin and tunicamycin. Biochim. Biophys. Acta. 837:123-134.

35. Amri, E.-Z., C. Vannier, J. Etienne, and G. Ailhaud. 1986. Maturation and secretion of lipoprotein lipase in cultured adipose cells. II. Effects of tunicamycin on activation and secretion of the enzyme. Biochim. Biophys. Acta. 875:334-341.

36. Olivecrona, T., S. S. Chernick, G. Bengtsson-Olivecrona, M. Garrison, and R. O. Scow. 1987. Synthesis and secretion of lipoprotein lipase in 3T3-L1 adipocytes: demonstration of inactive forms of lipase in cells. J. Biol. Chem. 262:10748-10759.
37. Ong, J. M., and P. A. Kern. 1989. The role of glucose and glycosylation in the regulation of lipoprotein lipase synthesis and secretion in rat adipocytes. J. Biol. Chem. 264:3177-3182.

38. Vannier, C., E.-Z. Amri, J. Etienne, R. Negrel, and G. Ailhaud. 1985. Maturation and secretion of lipoprotein lipase in cultured adipose cells. I. Intracellular activation of the enzyme. J. Biol. Chem. 260:4424-4431.

39. Greenwood, M. R. C. 1985. The relationship of enzyme activity to feeding behavior in rats: lipoprotein lipase as the metabolic gatekeeper. Int. J. Obes. 9(Suppl. 1):67-70.

40. Schwartz, R. A., and J. D. Brunzell. 1981. Increase of adipose tissue lipoprotein lipase activity with weight loss. J. Clin. Invest. 67:1425-1430. 